\title{
Synthesis of Aluminum-doped Zinc Oxide Nanowires Hydrothermally Grown on Plastic Substrate
}

\author{
Concepción Mejía García ${ }^{1}$, Elvia Díaz Valdés ${ }^{1}$, Ana Ma. Paniagua Mercado ${ }^{1}$, Arturo F. Méndez Sánchez ${ }^{1}$, \\ José A. Andraca Adame', Velumani Subramaniam ${ }^{3}$, Josué Romero Ibarra ${ }^{3}$ \\ ${ }^{1}$ Departamento de Física, Escuela Superior de Física y Matemáticas, Edif. UPALM Col. San Pedro Zacatenco, Deleg. GAM, México \\ ${ }^{2}$ Centro de Nanociencias y Micro y Nanotecnologías del IPN, UPALM, Luis Enrique Erro S/N, México \\ ${ }^{3}$ Depto. de Ing. Eléctrica, Sección de Estado Sólido, Av. IPN No. Col. San Pedro Zacatenco, México \\ Email: concepcionmejia@gmail.com
}

Received 2012

\begin{abstract}
We report the synthesis of undoped $\mathrm{ZnO}$ and $\mathrm{Al}$-doped $\mathrm{ZnO}(\mathrm{ZnO}: \mathrm{Al})$ nanowires grown using a two-step process: (a) preparation of the seed layer, and (b) growth of the nanostructures. In the first step, $10 \mathrm{mM}$ solutions of zinc acetate dihydrate and 1-propanol were spin coated on polyethylene terephthalate (PET) substrate at $2000 \mathrm{rpm}$ by $30 \mathrm{~s}$. Vertical nanowires were then grown by dipping the substrates in an equimolar solution of zinc nitrate hexahydrate and hexamethylenetetramine. As doping source, aluminum nitrate nonahydrate powders were added in the solution. In the solutions, Al doping concentrations were established as $0.5 \mathrm{At} \%, 1.0 \mathrm{At} \%$, 2.0 At $\%$ and 3.0 At $\%$, respectively. The hydrothermal process were carried out with a commercially microwave at $140 \mathrm{~W}$ power setting. The nanowires were characterized optically and morphologically. XRD patterns show the presence of $\mathrm{ZnO}, \mathrm{Zn}(\mathrm{OH})_{2}$ and $\mathrm{Zn}_{6} \mathrm{Al}_{2} \mathrm{O}_{9}$. Scanning electron microscopy analysis showed that the size of $\mathrm{ZnO}$ nanowires was $50 \mathrm{~nm}$ in diameter. The undoped $\mathrm{ZnO}$ and $\mathrm{ZnO}: \mathrm{Al}$ nanowires bandgap energy was obtained from optical transmission spectra.
\end{abstract}

Keywords: Nanowires; ZnO; ZnO:Al Nanowires; Spin Coating; Hydrothermal Process

\section{Introduction}

$\mathrm{ZnO}$ is a promising material in the field of short wavelength optoelectronics due to its wide and direct bandgap of $3.37 \mathrm{eV}$ at room temperature [1]. Nanostructures based on this semiconductor offer the benefit of material quality leading to improved device efficiency such as UV nanolasers, field effect transistors and solar cell electrodes [2,3]. Doping $\mathrm{ZnO}$ is an effective method in order to modify the physical properties. The $\mathrm{ZnO}: \mathrm{Al}$ nanowire arrays are capable of reaching the highest conductivity without deterioration in optical transmission and cristallinity, and thus are promising candidates for field emision displays. $\mathrm{ZnO}: \mathrm{Al}$ nanostructures have been prepared by different methods (e. g. pulse laser deposition and magnetron sputtering) and investigated the effect of the $\mathrm{Al}$ doping concentrations on the structure. However these methods require complex procedures like high temperatures or vacuum.

The hydrothermal $\mathrm{ZnO}$ nanowire synthesis has advantages over the methods mentioned previously. Nevertheless, the time required for the synthesis takes several hours or days. An alternative to reduce process time is the use of the rapid microwave heating process. In this work, the hydrothermal method is performed with a commercially microwave oven for fast heating of the material. With this procedure the processing time, for $\mathrm{ZnO}$ and $\mathrm{ZnO}: \mathrm{Al}$ nanowires grown on PET substrates, is decreased.

The undoped $\mathrm{ZnO}$ and $\mathrm{ZnO}: \mathrm{Al}$ nanowires were characterized morphologically by scanning electron microscopy (SEM), structurally by X-ray diffraction and optically by transmission measurements.

\section{Experimental Procedure}

Undoped $\mathrm{ZnO}$ and $\mathrm{ZnO}: \mathrm{Al}$ nanowires were grown hydrothermally based on the method developed by Husnu et al. [4]. This method consists of two-step process: (a) preparation of the seed layer, and (b) growth of the nanostructures. First, a $10 \mathrm{mM}$ solution of zinc acetate dihydrate and 1-propanol was prepared. The solution was then spin coated on PET substrate at 2000 rpm by $30 \mathrm{~s}$. After three cycles of spin coated deposition, the deposit on the substrate was annealed at $100^{\circ} \mathrm{C}$ during $5 \mathrm{~min}$, and then a seed layer was obtained on the PET substrate. Secondly, the substrate was dipped in a mixture of equimolar 25 $\mathrm{mM}$ zinc nitrate hexahydrate $\left(\mathrm{Zn}\left(\mathrm{NO}_{3}\right)_{2} \cdot 6 \mathrm{H}_{2} \mathrm{O}\right)$ and hexamethylenetetramine (HMTA) solution in deionized water. As the doping source, aluminum nitrate nonahydrate $\left(\mathrm{Al}\left(\mathrm{NO}_{3}\right)_{3} \cdot 9 \mathrm{H}_{2} \mathrm{O}\right.$ powders were added in the solution. In the solutions, $\mathrm{Al}$ doping concentrations were established as 0.5 At \%, 1.0 At \%, 2.0 At $\%$ and 3.0 At $\%$, respectively. Table 1 shows Al concentrations for the $\mathrm{ZnO}$ :Al nanowire samples. The hydrothermal process was carried out heating with a commercially microwave oven at $140 \mathrm{~W}$ power setting at atmospheric pressure during $10 \mathrm{~min}$. The X-ray patterns were measured in Grazing-incidence smallangle X-ray scattering (GISAXS) with XPert PRO Diffractometer from Panalytical using $\mathrm{Cu}$ radiation $(\mathrm{K} \alpha=1.54 \AA)$, it is a technique used to study nanostructured surfaces and thin films. The sample was placed in one degree $\left(\theta=1^{\circ}\right)$. X-Ray mirror and soller slit $(0.04 \mathrm{Rad})$ in incident optic and PIXcel ultrafast $\mathrm{X}$ ray detector for diffracted optic were used. The step size was 0.05 and $300 \mathrm{~s}$ for time. $45 \mathrm{kV}$ and $40 \mathrm{~mA}$ were used for tube 
power. Optical transmission measurements were performed in a UV/VIS spectrometer Lambda Perkin Elmer in the region of $300 \mathrm{~nm}$ to $1100 \mathrm{~nm}$. SEM micrographs were obtained with secondary electrons in a Zeiss MOD Auriga 39-16 microscopy.

\section{Results and Disscusion}

\subsection{X-Ray Diffraction Patterns}

Figure 1 shows the X-ray diffraction patterns of the PET substrate, the undoped $\mathrm{ZnO}$ nanowires (sample $\mathrm{Z1}$ ) and the $\mathrm{ZnO}: \mathrm{Al}$ (sample Z3). There were identified several crystalline phases as $\left(\mathrm{C}_{10} \mathrm{H}_{8} \mathrm{O}_{4}\right)_{\mathrm{n}}, \mathrm{ZnO}, \mathrm{Zn}(\mathrm{OH})_{2}$ and $\mathrm{Zn}_{6} \mathrm{Al}_{2} \mathrm{O}_{9}$. The PET phase $\left(\mathrm{C}_{10} \mathrm{H}_{8} \mathrm{O}_{4}\right)_{\mathrm{n}}$ has a triclinic structure with crystal lattice dimension of $4.53 \AA \times 5.92 \AA \times 10.77 \AA\left(99.92^{\circ} \times 118.62^{\circ} \times 111.37^{\circ}\right)$. Its reflections of highest intensities are located at $22.72^{\circ}$ and $26.11^{\circ}$ 2 degrees and its corresponding hkl are (-110) and (100). The $\mathrm{ZnO}$ phase has a hexagonal structure with crystal lattice dimension of $3.25 \AA \times 3.25 \AA \times 5.20 \AA\left(90^{\circ} \times 90^{\circ} \times 120^{\circ}\right)$. The reflections of highest intensities are located at $31.76^{\circ}, 34.32^{\circ}$ and $36.25^{\circ} 2$ degrees and its hkl are (100), (002) and (010) respectively. The $\mathrm{Zn}(\mathrm{OH})_{2}$ phase has a tetragonal structure with crystal lattice dimension of $8.22 \AA x 8.22 \AA \times 14.34 \AA$ $\left(90^{\circ} \times 90^{\circ} \times 90^{\circ}\right)$. The reflections of highest intensities are located at $19.58^{\circ}, 24.90^{\circ}$ and $30.57^{\circ} 2$ degrees and its corresponding hkl are (112), (004) and (213). The reflections of highest intensities, of the $\mathrm{Zn}_{6} \mathrm{Al}_{2} \mathrm{O}_{9}$ phase, are at $32.17^{\circ}, 34.60^{\circ}$ and $36.49^{\circ} 2$ degrees. Figure 2, in the region from $30^{\circ}$ to $60^{\circ} 2$ degrees, shows in detail the presence of the crystalline phases identified in the samples. From sample Z1 we appreciate reflections associated to PET, as well as, reflections of $\mathrm{ZnO}$. Sample $\mathrm{Z} 3$ shows the presence of the $\mathrm{ZnO}, \mathrm{Zn}_{6} \mathrm{Al}_{2} \mathrm{O}_{9}$ and $\mathrm{Zn}(\mathrm{OH})_{2}$ crystalline phases. It is clearly observed that when the $\mathrm{ZnO}$ is doped with $\mathrm{Al}$ the $\mathrm{Zn}_{6} \mathrm{Al}_{2} \mathrm{O}_{9}$ phase is formed. The reflections of $\mathrm{Zn}_{6} \mathrm{Al}_{2} \mathrm{O}_{9}$ phase are observed as shoulders in the bands of $\mathrm{ZnO}$, in addition to the reflections present at $47.56^{\circ}$ and $56.78^{\circ} 2$ degrees. On the other hand, additional reflections from $\mathrm{Zn}(\mathrm{OH})_{2}$ can be observed at $42.84^{\circ}, 45.76^{\circ}$ and $50.91^{\circ} 2$ degrees and its hkl are (314), (107) and (008) respectively.

\subsection{Scanning Electron Microscopy}

Figure 3 shows the typical SEM images of the undoped $\mathrm{ZnO}$ (sample Z1) and $\mathrm{ZnO}: \mathrm{Al}$ (sample Z4) arrays grown at $140 \mathrm{~W}$ by $10 \mathrm{~min}$. Figure 3(a) shows the SEM image of a high density of vertically undoped $\mathrm{ZnO}$ nanowire arrays It can be seen that the nanowires grown vertically aligned on the PET substrate. The diameters of the $\mathrm{ZnO}$ nanowires are less than $50 \mathrm{~nm}$. Figure 3(b) shows the image of $\mathrm{ZnO}$ doped with 2.0 At \% Al.

Table 1. Conditions of growth parameters.

\begin{tabular}{cc}
\hline Sample & Al At \% \\
\hline Z1 & undoped \\
Z2 & 0.5 \\
Z3 & 1.0 \\
Z4 & 2.0 \\
Z5 & 3.0 \\
\hline
\end{tabular}

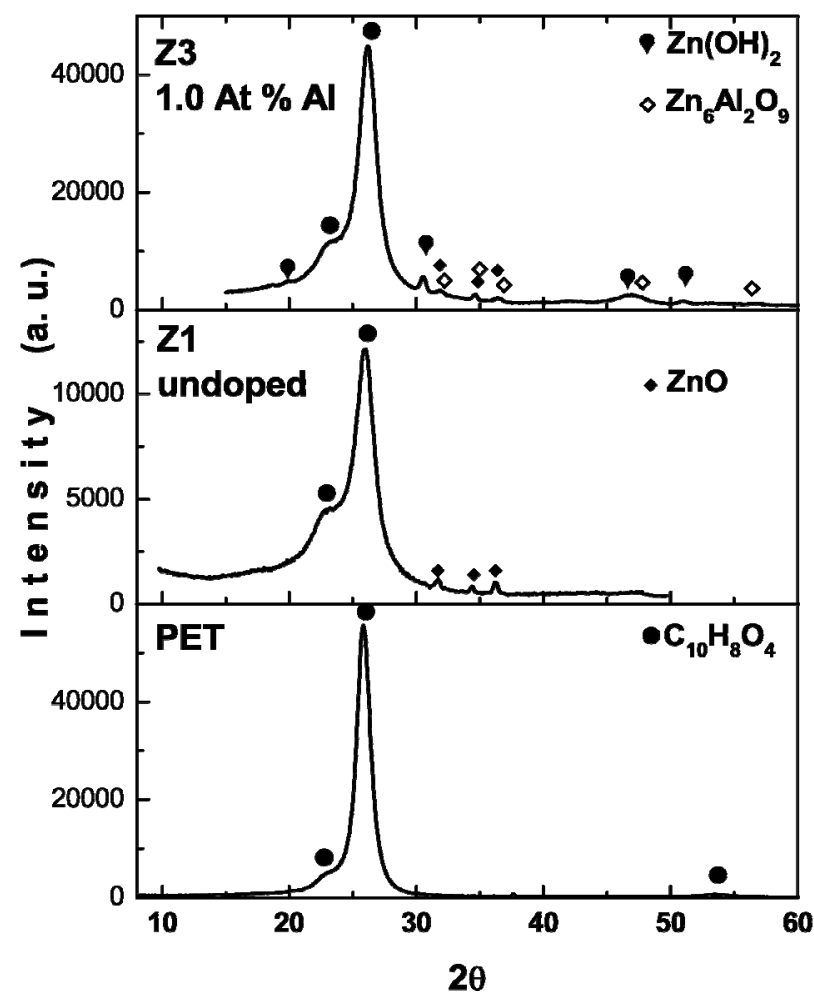

Figure 1. X-Ray diffraction patterns of the PET substrate, undoped $\mathrm{ZnO}$ (sample Z1) and ZnO:Al at 1.0 At \% (sample Z3) processed in a microwave oven at $140 \mathrm{~W}$ during $10 \mathrm{~min}$.

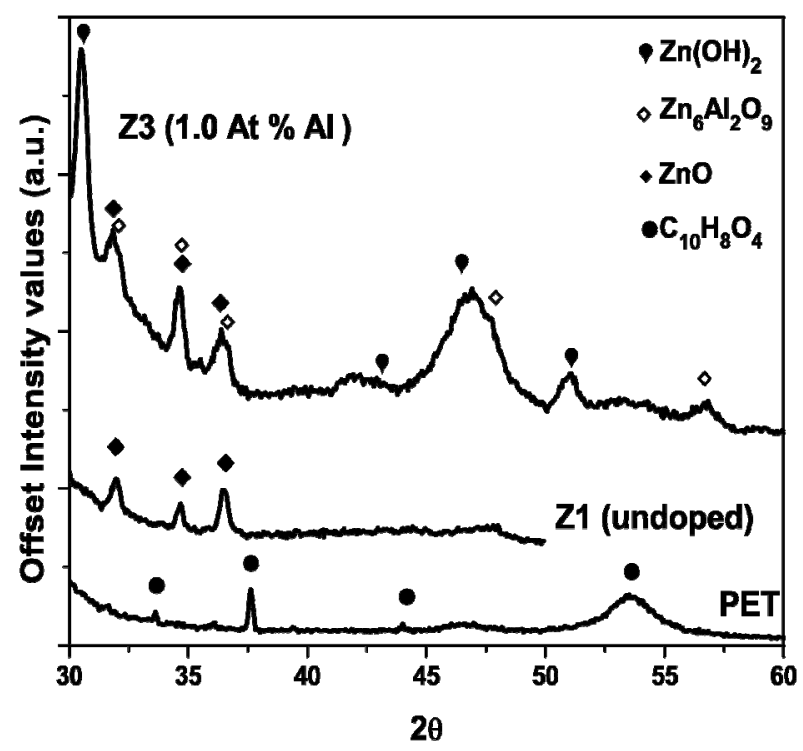

Figure 2. X-Ray diffraction patterns, in the $30^{\circ}$ to $60^{\circ} 2 \theta$ region of the PET substrate, undoped $\mathrm{ZnO}$ (sample $\mathrm{Z1}$ ) and $\mathrm{ZnO}$ : Al at 1.0 At $\%$ (sample $\mathrm{Z3}$ ) processed in a microwave oven at $140 \mathrm{~W}$ during 10 min.

Besides the high density of $\mathrm{ZnO}$ nanowire arrays, it can be found that there are other nanostructures like nanosheets. Due to the doping with $\mathrm{Al}$ ions, the coexistence of the $\mathrm{ZnO}$ nanowires and nanosheets was observed. We also observed that the number of nanosheets was increasing with doping concentration. 


\subsection{Optical Transmission}

Figure 4 shows the optical transmission spectra in the range of 300 and $1100 \mathrm{~nm}$ for all samples. It can be observed a good transparency from the samples doped with Al in comparison with the undoped $\mathrm{ZnO}$ sample $\mathrm{Z1}$. In our previous work, an undoped $\mathrm{ZnO}$ sample grown on glass substrate with a $140 \mathrm{~W}$ and $15 \mathrm{~min}$, an optical transmission around $60 \%$ was reported [5]. In this work it was possible to obtain $\mathrm{ZnO}$ wires with the same power setting but less time $(10 \mathrm{~min})$ grown on PET substrate. With $\mathrm{Al}$ doping concentration, the optical transmission was increased from $5 \%$ to $65 \%$.

From these spectra it can be seen that the absorption edge is around $360 \mathrm{~nm}-390 \mathrm{~nm}$. From the transmission spectra the energy band gap $\mathrm{E}_{\mathrm{g}}$ was obtained for each sample. Table 2 shows these results. It was no possible to determine the energy band gap of the undoped sample through this method. The energy band gap decreases when the $\mathrm{Al}$ concentration increases.

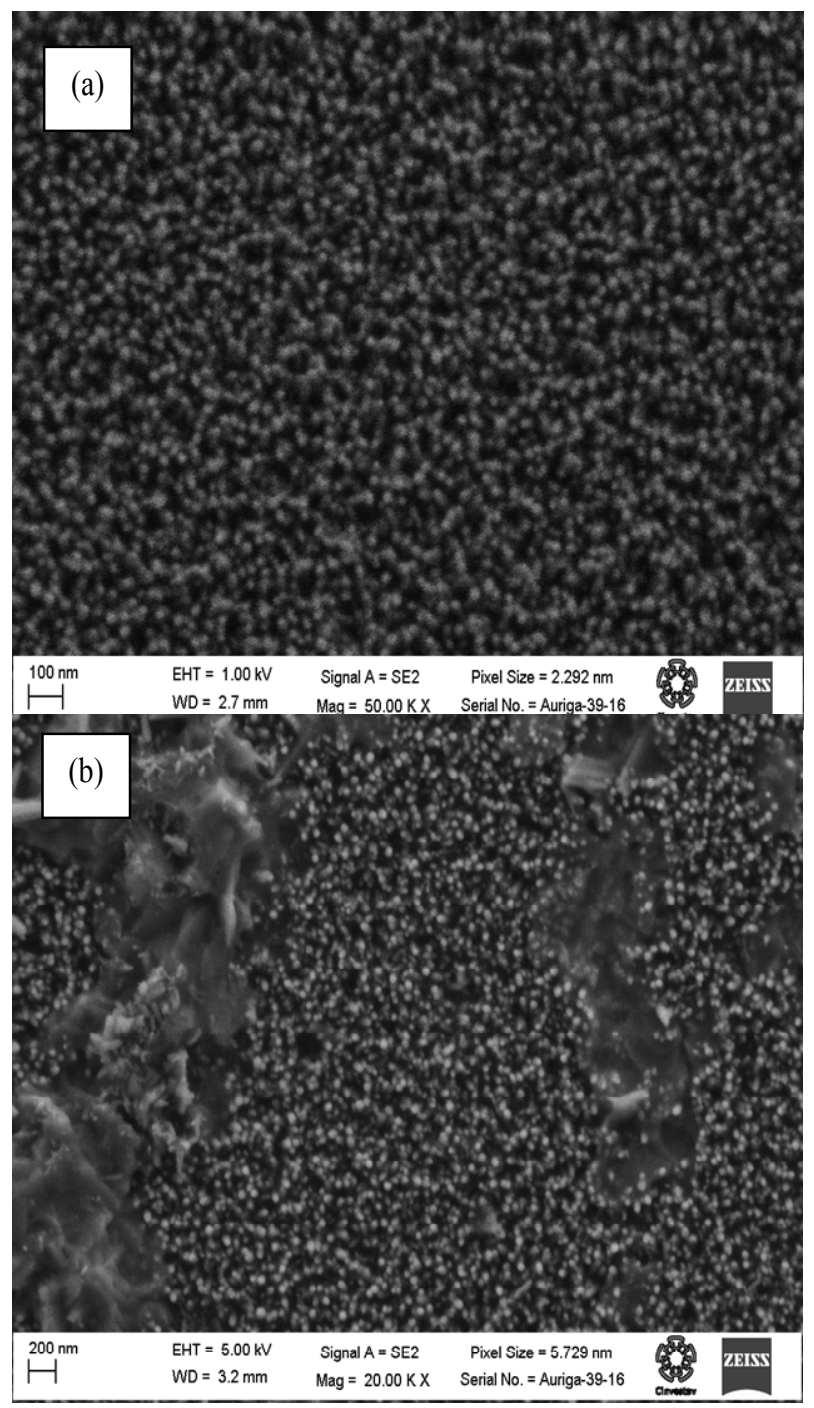

Figure 3. Scanning electron microscopy images of the undoped $\mathrm{ZnO}$ nanowires (sample $\mathrm{Z1}$ ) and $\mathrm{ZnO}$ :Al (sample $\mathrm{Z4}$ ) grown on PET substrate at $140 \mathrm{~W}$ for $10 \mathrm{~min}$.

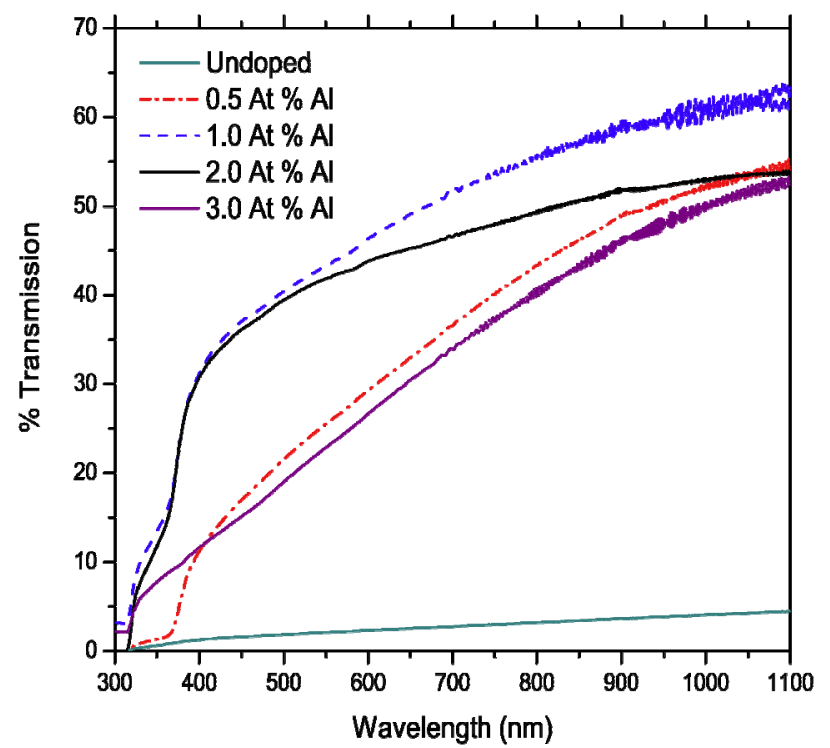

Figure 4. Optical transmission spectra of undoped $\mathrm{ZnO}$ and ZnO:Al nanowires on PET substrate.

Table 2. Band gap energy of the undoped and $\mathrm{ZnO}$ : $\mathrm{Al}$ nanowires.

\begin{tabular}{cc}
\hline Sample & Eg(eV) \\
\hline $\mathbf{Z 1}$ & - \\
$\mathbf{Z 2}$ & 3.32 \\
$\mathbf{Z 3}$ & 3.32 \\
$\mathbf{Z 4}$ & 3.33 \\
$\mathbf{Z 5}$ & 3.27 \\
\hline
\end{tabular}

\section{Conclusions}

Undoped $\mathrm{ZnO}$ nanowire arrays and $\mathrm{ZnO}: \mathrm{Al}$ nanostructures grown on PET substrate were successfully synthesized by the hydrothermal method using a commercial microwave oven. With just $10 \mathrm{~min}$ of heat treatment, $\mathrm{ZnO}$ nanowires with less than $50 \mathrm{~nm}$ of diameter were obtained. The coexistence of the nanowires and nanosheets was observed by introducing $\mathrm{Al}$ ions. Optical transmission spectra showed that $\mathrm{ZnO}$ nanowire arrays doped with $\mathrm{Al}$ increases the optical transmission in comparison with the arrays of undoped $\mathrm{ZnO}$. The $\mathrm{ZnO}$ :Al nanostructures treated with the hydrothermal method showed a great promise for applications as flexible devices, processed with low power, short growth time, and low cost.

\section{Acknowledgements}

The authors thank Esteban Basurto Cazares for the technical support.

\section{REFERENCES}

[1] Lee C. Y., Li S. Y., Lin P., Tseng T. Y., IEEE Trans. NanoTechnol. 2006, 5, 216 . 
[2] Lai E., Kim W. Yang P., Nano Res, 2008, 1:123-128.

[3] Lupan O., Guérin V. M., Tiginyanu I. M., Ursaki V. V., Chow L., Heinrich H., Pauporté, Journal of Photochemistry and Photobiology A: Chemistry , 2010, 211, 65-73.
[4] E. U. Husnu, Pritesh H., Nalin R., Sharvari D., William I., Gehan A. J. A., Nanotechnology 2008, 19, 255608.

[5] Mejía García C., Díaz Valdés E., Ortega Cervantes, Basurto Cazares E., J. Chem. Chem. Eng. 2012, 6, 61-64. 